\title{
ETHICAL INCLUSIVE CURRICULA DESIGN: CONVERSATIONAL TEACHING AND LEARNING
}

\author{
P. R. Baron \\ Department of Electrical and Electronic Engineering Technology \\ University of Johannesburg \\ Johannesburg, South Africa \\ e-mail: pbaron@uj.ac.za
}

\section{ABSTRACT}

South African Public Universities are facing transitional challenges as they traverse uncharted territory in decolonising knowledge. The idea of decolonising knowledge brings with it the need to review curricula as well as the lecturer's pedagogy. A cybernetic approach using conversation theory is presented as a viable solution to inclusive and ethical contextual curricula design. Through conversation, contextual enquiries can be achieved which are then used as reference points in revising curricula. In this article, a report back on a recent curriculum re-design is presented. The results of this process have been positive with students demonstrating increased participation, personal responsibility, and higher motivation in performing assignments. Other positive features are that students introduce new and relevant topics into the curriculum. These topics are contextualized by the students (and teacher) allowing for student interpretations of the content in terms of their daily lives, i.e. the students populate the curriculum with experiences they have had within their communities. There is increased social engagement in the classroom with students also dialoging in community with one another and the teacher. The abstraction of the curriculum is reduced in turn increasing the familiarity and personalization of the module content areas. This personalization effect was found to improve memory retention of the module content as the grades were higher for the topics that were proposed by students.

Keywords: conversation theory, contextual teaching, cybernetics, curriculum design, decolonisation, ethics, heterarchy, humanising pedagogy, social justice.

\section{ETHICAL PEDAGOGY: TWO CHALLENGES}

New styles of university teaching and learning have emerged and educators have had to become more professional in their approach to teaching, matching their approach to research (Laurillard 2013). ${ }^{1}$ Lecturers who are highly specialised in their respective fields do not necessarily make good teachers; thus, there has been an increased focus on the educators' teaching methods and their fit for purpose in the context of the strategic goals of their respective universities. In South Africa, there is a need to rethink higher education, as colonial legacies still dominate most classrooms, which is problematic for a large proportion of the student population, whose 
African worldviews and heritage have mostly been ignored and/or deemed inferior. ${ }^{2}$ The apartheid regime also continued the undemocratic education system and its mostly exclusive approach to knowledge in South Africa. ${ }^{3}$ Now, 26 years after the abolition of apartheid, the enrolments at public universities do reflect a transformation with Black South Africans accounting for 68 per cent of enrolments, while Coloureds and Indians collectively count for 12 per cent (DoHET 2015, 13). For example, at the University of Johannesburg, which is the largest of the comprehensive contact universities, 83 per cent of students are black. ${ }^{4}$ Thus, in terms of demographics, there is an improvement; however, the signs and symbols, curricula contents, teaching styles, epistemology, language policies, amongst many other aspects, still perpetuate colonial legacies. ${ }^{5}$

Educators in South Africa who have opted to address their pedagogy in terms of the decolonisation agenda, face several challenges, two of which will be discussed in this article. The first challenge, is the acceptance that transmitting information is not teaching. Simply presenting information in front of the class or handing out notes is not teaching, and information is not knowledge. Knowledge requires a knower - a human to make sense of the information on offer, intermingling this information with one's own way of knowing and experiencing the world. The basis for this premise is that knowledge cannot be transmitted from one person to another but must be actively built up or created by the learner (Glasersfeld 2007). These ideas are not new, and many educators are adopting an approach that recognises this constructivist philosophy to knowledge creation.

The second challenge that is discussed in this article, is the goal of addressing social justice in the educator's pedagogy. This goal is tied to decolonisation of knowledge and is not clearly understood by many lecturers. ${ }^{6}$ My own view is that there was a disregard for African knowledge and worldviews in lieu of colonial values. To address social justice in an educational context, educators would need to aspire to a humanising pedagogy, whereby the worldviews of the groups who were unfairly treated (and disregarded) should be actively incorporated (and encouraged) in the classroom. Students should thus be the decolonisers who also provide the measure of the decolonisation and the achievement of social justice. Students are thus the main decolonising actors in the education system.

In this article, conversational teaching and learning is presented as an ethical approach that may achieve eclectic curriculum design that has scope for multiple inputs.

\section{Aims}

An implied methodology is presented as an approach to assist in dealing with the two challenges of knowledge creation and social justice in education. While the former obstacle - constructing 
knowledge in the classroom - is well researched and published (Glasersfeld 1992; Herr 2014; Baron 2016a) the latter challenge of addressing social justice in an educator's pedagogy is not (Baron 2016b). My aim to is present an ethical heterarchical approach to knowledge creation that achieves social justice for the actors within the tertiary education system.

\section{Methodology}

The implied method presented is heterarchical conversational teaching and learning ${ }^{7}$ from a cybernetic perspective. Conversation Theory (CT) is used as a framework for a contextual approach to curricula design embracing the worldviews of those who sit in the classrooms, in turn valuing the students' existing knowledge, culture, and life experience (Bartolome 1994). Contextualising curricula requires an enquiry into the epistemologies of the students (explained in the article). Through conversations, contextual enquiries can be achieved which are then used as reference points in revising the curriculum.

In this article, a report back on a recent curriculum re-design is discussed. A strategic approach to contextualising an electrical engineering curriculum is thus presented, including the challenges faced in attempting this approach as well as unpredictable and surprising outcomes.

\section{Scope and purpose}

The need to address social justice is relevant in a South African context owing to the historic injustices that have ensued. However, the challenge of inclusive approaches to learning are not only relevant to South Africa. Many universities worldwide have classrooms that are populated with a variety of cultures yet there is a single dominant discourse on offer. There may be a lecturer who has a different background to that of the learners and presents the course content according to his/her own dominant discourse (or that of the university). ${ }^{8}$ The lecturer's pedagogy may be unfamiliar to the student group/s, resulting in students not being prepared for the language and examples used by their teachers. These differences in language and methods of understandings challenge the learning process. Conversational teaching is therefore presented as an approach that aids in bridging the gaps between different worldviews.

In this article it is argued that curricula that is designed in a vacuum is an unethical activity and that an open, inclusive, and eclectic approach may achieve ethical pedagogy, as the worldviews on offer in the classroom are included in the curricula. Hence, ethical pedagogy becomes a relevant topic when educators are attempting to review their teaching approach and curricula design. 


\section{Important terms}

\section{Curriculum}

In the context of this article, the term "curriculum" represents all the facets of teaching and learning, including the course content or syllabus, teaching approach, and assessment methods. However, owing to space limitations, the implied methodology in this article focusses primarily on a conversational approach to populating the course content or syllabus only.

\section{Epistemology}

The term "worldview" refers to the person's prior knowledge and past learning experiences, which in turn influence how one interprets and understands new information. A person's worldview is thus a factor in how new information is understood (MacIntyre 1987). The German word for worldview is weltanschauung, which is commonly used in philosophy texts owing to a wider definition which describes both the individual and society as being linked to cultural understandings, beliefs and values. These understandings, which are often tacit, originate from the vast works that poets, mythical writers, and story tellers have built up, to a point where it becomes formalised as an accepted linguistic domain for that society or culture (MacIntyre 1987, 392). The cultural understandings form a foundation and justification system that seems unarguable, unless the arguments are made within the same frame of reference or epistemology. MacIntyre believes that these linguistic domains determine the way we carry out our activities including laws, ethics, rationality, beliefs and values. Our weltanschauung or even our cosmic order as MacIntyre termed it, is dependent on our linguistic domain. Thus, language and how people attach meaning to spoken words should also be acknowledged in educational systems. Epistemology, or how we understand knowledge, is thus an important part of a teacher's pedagogy. This is particularly relevant in South Africa with 11 official languages and many cultural groups who are present in the classrooms.

\section{Reflexion}

The term "reflection" has become commonplace in academia with most master's students being told to reflect on their work. This entails reviewing and thinking about one's position and how the scholar has influenced his/her work along the research journey-observer effect. ${ }^{9}$ The observer effect is a troubling aspect of research, especially in the social sciences. Although Schön (1983) used the term "reflective", I prefer von Foerster's use of the word which highlights the inclusion of the relationship of oneself to the context and to others as well. The word thus changes to reflexive which is used to denote that there is a dynamic circular loop of 
contemplation and change invoked from several sources (Glanville 2013; Foerster 1991). This distinction is important in the context of this article. When the curriculum is opened to the students, several reflection loops occur - we reflect on one another's reflections. Since this happens in community with one another, it is dynamic and informationally open as recursive improvements take place with the aim of acknowledging difference.

\section{Heterarchy}

In terms of educational contexts, a heterarchical approach allows for agreement on the roles and responsibilities of the participants within the educational system (Richards 2014; Baron 2016a). Heterarchy does not mean there is no leader. Rather, it means that the participants have opted to select their leader whose role is to regulate the variety of learnings in a democratic course of action. The leader is usually the person who can assist the other participants in reaching their goals. The participants have a claim in the governance of the system, and thus equality is important.

\section{The actors within the educational performance}

“Learning begins with each student's aims or outcomes.” Gordon Pask (1975a, 45).

In any educational system there are participants or actors. I have opted for the term "actors", borrowing it from Austin who stated $(1962,138)$ :

\footnotetext{
"Once we realize that what we have to study is not the sentence but the issuing of an utterance in a speech situation, there can hardly be any longer a possibility of not seeing that stating is performing an act."
}

Each person in the education system is in effect an actor with his/her own aims. Each person has a role to play in the teaching and learning system and is thus part of the system. Following a traditional model of education suggests that the teacher is the leader in the classroom and directs the learning process. However, in terms of decolonising the curriculum, the role of the teacher should be somewhat different. If the aim is to contextualise the curriculum, embracing the previously disregarded worldviews, then a form of engagement would need to take place whereby the other actors (students) are provided with a forum to actively engage and co-create the syllabus. This means that heterarchy replaces hierarchy whereby students are now equally important contributors in the system. The system is no longer linear (teacher to student), it is circular and multifaceted (teacher to student, student to teacher, and student to student). 
Having presented this pedagogy at universities both locally and internationally, there are common questions that arise from this conversational approach to teaching and learning. These include:

a) How could students who have limited knowledge on the topics in the classroom become the co-authors of a curriculum?

b) How do you get students to take part in classroom activities when they barely attend classes in the first place?

c) Do the students really want to engage in the classrooms?

d) How do you adjust the syllabus when it is a fixed part of the curriculum and accreditation bodies audit the outcomes?

e) How do you assess the students' knowledge or understanding?

In the remainder of this article, points a) to d) will be addressed. Point e) has been addressed by the author in a stand-alone publication (Baron 2016a). To tackle the first question relating to limited knowledge of students (a), a metaphoric nunatak is presented next.

\section{STUDENTS AS NUNATAKS}

The term "nunatak" refers to an outcrop of rock that is usually in an isolated space (see Figure 1). Nunataks are often used as landmarks or reference points in glaciers as they do not have ice covering them. They are often the only places where vegetation grows in an otherwise hostile environment. Using nunataks as a metaphoric example of knowledge, one may think of the open space around the nunatak as unknown territory - lack of knowledge or specialisation while the nunatak represents higher knowledge or already present knowledge. For example, in an electrical engineering module, a student may demonstrate knowledge of mathematical rules, being able to solve equations, but has limited knowledge of current, voltage, and other electrical components. This mathematical knowhow could be considered a nunatak while the limited knowledge in the topics of electrical circuit theory represents the open space or plains that are shown in the images of Figure 1. Since each student sitting in the classroom has his/her own unique past lived experiences and knowledge platform, students should not be seen as blank slates. ${ }^{10}$

For several years I have asked students to propose topics for the module called Computer Network Systems. ${ }^{11}$ In this module, students have proposed relevant and cutting-edge topics every semester. For example, students provided the following topics for their assignments in 2016: Bluetooth encryption for wearables, ${ }^{12}$ underwater sea cabling, WIFI security, and 
database security. From these topics it is evident that security and cryptography was important to the students. During the classroom conversations students spoke of how they were concerned about the data breaches that have taken place in the public domain and that data security is important to them. The module of network systems does not have the topics that the students suggested yet these are relevant topics. ${ }^{13}$ From this example, I argue that students act as reference points in informing the curriculum in a direction that is relevant to them. The teacher moderates this trajectory by determining if the topics are viable for industrial partners who will mostly employ the students upon graduation.

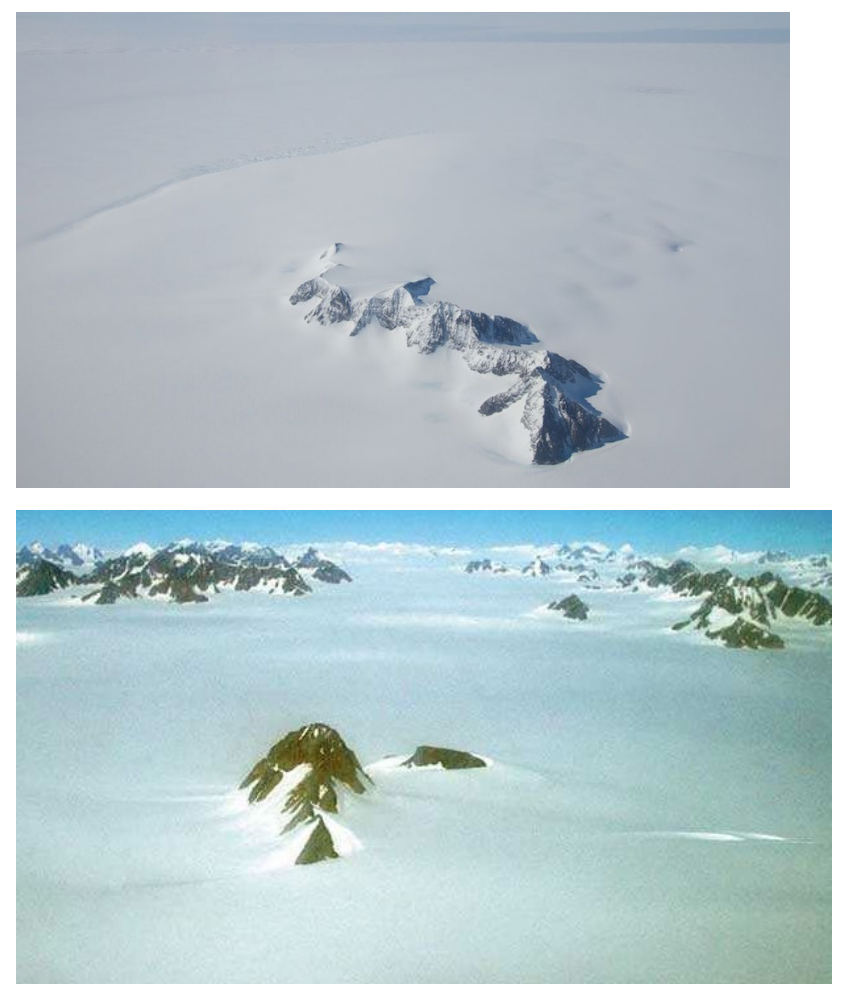

Figure 1: Graphical examples of nunataks.

The point of the nunatak metaphor is that students usually do have some knowledge in the topic of study, which is the knowledge that the educator should use as the reference point or foundation for the next topic in the syllabus. For example, students understand the topic of mechanical friction. Physical friction is easily demonstrated in a classroom - moving one's hand over sandpaper, or scraping one's shoe on the ground, and so forth. However, many students do not grasp electrical resistance and how it impacts electrical current in a circuit. By using mechanical friction as a basis for the explanation (which the students already understand), electrical friction or resistance can be explained in terms of the students understanding of mechanical frication thus bridging the gaps in these two topics. ${ }^{14}$ 
If educators view the students as blank slates, they miss an opportunity to co-create the curriculum. They also miss the opportunity to gain an understanding of what areas of the syllabus are not understood by the students or which topics should be changed. Thus, the point of co-creating the syllabus is also meant to inform the lecturer on the parts of the curriculum that are troubling for the students prior to assessments. When the lecturer engages with the students, attempting to understand the students' understanding of the syllabus, the lecturer will quickly identify parts of their lessons which are ineffective. I am surprised that lecturers rarely ask their students how they experienced the lecture, what they learned, what improvements can be made, and so forth. This heterarchical approach allows students to be included in the education system as co-creators and not simply receivers of information. Since the students are sitting in the classes, they should have a say in what they would deem good teaching, as the students' ability to learn impacts the teacher's wellbeing (Baron and Baron 2019).

The second question in the aforementioned list refers to student involvement in the class (b). When educators acknowledge that students have knowledge about the world, albeit not specialised knowledge in the field of study, educators in turn become open to hearing the students' stories. The next section addresses how educators may invite students to engage in the classroom and hear these stories.

\section{ETHICAL ENGAGEMENT WITH THE ACTORS IN THE EDUCATIONAL SYSTEM}

"It's not what you look at that matters, it's what you see." (Henry David Thoreau 2006, 102)

I am often asked how I engage with students and get them to participate in the class (point b). Cybernetics is an interdisciplinary approach or philosophy that I attempt to enact in my pedagogy. Cybernetics deals with circularity, form and patterns, communication systems, and observer dependence. One area of cybernetics is conversation theory. Conversation theory has its roots in Luria's (1961) research, but also in the works of Piaget (1959), Landa (1971), Kelly (1955), and Bateson (1972), as well as the information processing approaches of Broadbent (1971), Miller, Galanter and Pribram (1960), and Welford (1968), amongst others. Conversation theory acts as a framework for ethical engagement with the learners to embrace their epistemology. The aim is to move away from a one-size-fits-all paradigm to a humanising approach which addresses the moral responsibility of educators enacted in a careful engagement (del Carmen Salazar 2013).

\section{Cybernetics and conversation theory}

Human linguistic communication has a purpose. Conversations provide a context for the human 
world and become the realm which we inhabit. Our languaging is our manner of existence (Maturana 1997) ${ }^{15}$ bringing forth our self-consciousness. The conversation is the fundamental unit of enquiry for investigating human learning (see McCulloch 1965). It offers people the means for self-organising their own change (Thomas and Harri-Augstein 2001, 952). Conversation theory focusses on the architecture of conversations, the creation of knowing, and the evolution of perspectives (Pangaro 2001, 802). Gordon Pask (1975a, 1975b, 1976a, 1976b) studied conversations and how people learn. Pask (1976a, 122) argued that each person has their own unique learning style which cannot be directly known. ${ }^{16}$ A person cannot know how someone else thinks, but observers may gain some understanding of the thought processors (brain/mind) when the processes are exteriorised. Exteriorising the process entails conversations, as each person has an opportunity to engage and explain their understandings. Conversations are not objective as they are shared between those who participate in conversation, in what Glanville (2008) calls "in the between". The conversation is thus not owned by any single party, it is not the lecturer's nor the students'. Meaning is negotiated along the path. Language is thus an important feature in conversation theory as a person's use of language often translates to mean a different lived experience. This lived experience is unknowable unless the participants in the conversation express how they understand topics and provide contextual information which gives rise to their understandings. In this recursive process, the parties to the conversation begin to understand the understandings of the other, keeping in mind that each person's understanding is only a reflection of his/her own understanding of the understandings on offer in the conversation. This is a circular process allowing for mutual learning and reflexion. The lecturer learns about the understandings of the students and vice versa as they reflect on each other's comments.

The purpose of the conversation is to get some idea of the other person's/student's world. It is not to interrogate, control, or manipulate. It is thus imperative to acknowledge that a person's worldview arises out of their past lived experiences and that negating this worldview is also negating a person's background. Thus, conversations have an ethical component, which is particularly relevant in a South African context, considering the decolonisation of knowledge agenda. Since a conversation is not one-sided, there should not be a dominant discourse. Variety and mutual learning is valued as the curriculum and understandings surrounding the curriculum are embraced and adjusted by other worldviews. With every person experiencing their life differently, there exist multitudes of worldviews. Conversation theory provides various tools that educators and students may use to assist in their communication.

One tool is called "Teachback" which was developed by Gordon Pask and Bernard Scott (Pask 1976a, 1976b; Scott 2000). Teachback is a method in which, after the teacher has 
presented to the learners the topics aligned to the achievement of the learning outcomes, the learner is invited to teach back his/her understanding of this material/information to the teacher. When the students teach back to the class, they use their own words and own methods of understanding. This is what Pask refers to as the exteriorising of the mental processes which the teacher and students may use to improve the course content. Teachback has a variety of uses, including content contextualisation, social learning, ${ }^{17}$ language practice, assessment, and improved memory retention ${ }^{18}$ (Baron 2016a).

\section{CURRICULA DESIGN AS A CONVERSATION: AN EXAMPLE}

"Fundamentally, a university is a community holding conversations about knowledge." (Sir John Daniel 1998, 12)

There is a module called Electrical Protection III in the National Diploma qualification (Electrical Engineering). In this module there is a topic on earthing and lightning protection. To follow, is an example of how the earthing section was adapted using conversational teaching and learning.

Figure 2 is a representation of the process which is explained throughout the next section.

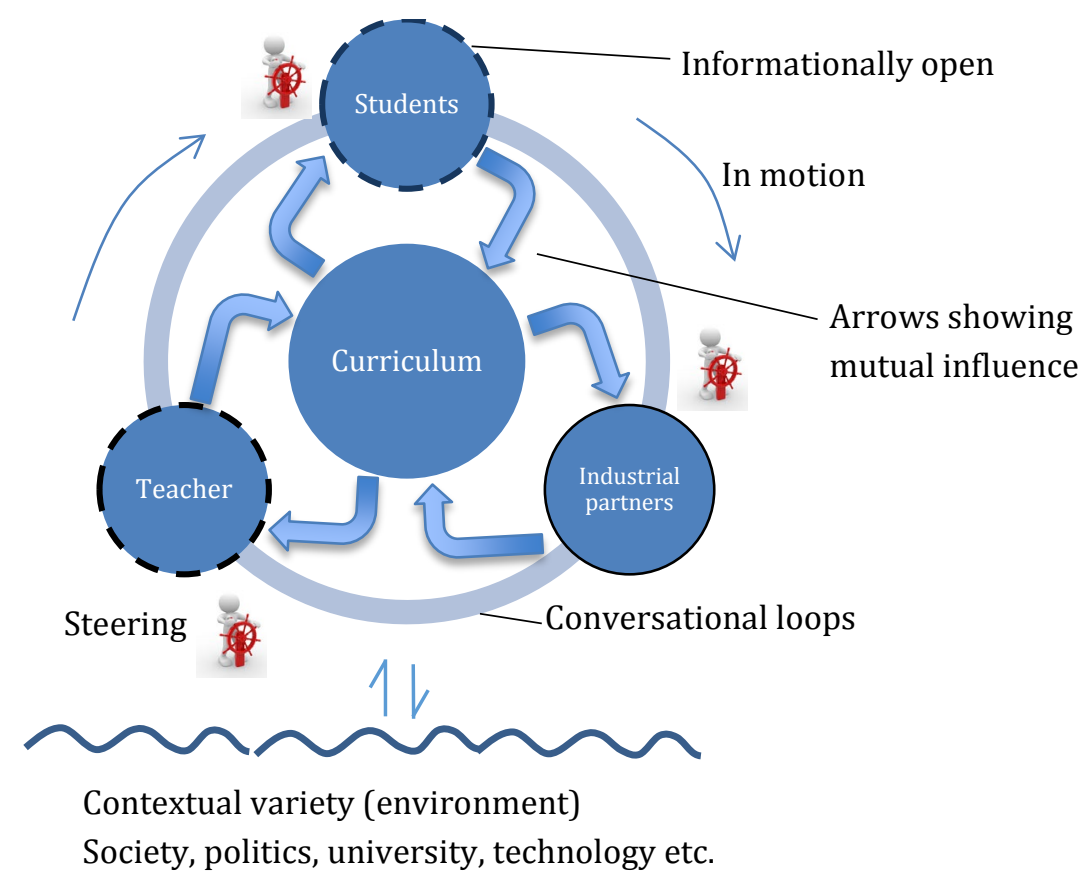

Figure 2: Curriculum design as a dynamic recursive reflexive process 


\section{Background to the topic of earthing}

Earthing of electrical equipment is used to protect people and equipment from lightning and electrical discharges. The goal of earthing is to provide the excess electrical current (fault current) with a low resistance path to the general mass of the earth. To achieve this goal, various techniques have been developed for which standards and codes have been established in the engineering community. ${ }^{19}$ However, owing to the unpredictability of weather and lightning discharges, as well as the uniqueness of buildings and sites that need to be earthed, the topic of earthing is not an exact science. Good examples of earthing that students should learn are substations, power stations, and buildings; however, these places are mostly inaccessible to people as the earthing is installed during the construction phase of the site. Textbooks on this topic are written for industrial applications.

\section{Conversation on earthing}

The following is an example of a conversation that was used to redesign the syllabus on earthing: ${ }^{20}$

Teacher (T): "Earthing is the topic of study today. Tell me what you know about this topic."

Student 1 (S1): "It's when you connect the copper wire to the chassis so that current can flow to ground."

T: "How do you do this. How do you "connect" the copper wire?"

S2: "You must bond the cable."

T: "Can anyone tell me what it means to bond cable?"

S2: "You join them to the metal."

T: "How and which metal?"

S3: "You must bolt them together to the chassis metal."

T: "Can I weld them or solder them too?"

S3: "If they are electrically connected its fine."

T: "Once its electrically connected, then what?"

S4: "When the fault occurs, the current can flow in the cable and then in the chassis."

T: "But how does the current flow to ground, as that's what you said in the beginning."

S1: "There must be a connection to the earth as well."

T: "How do you connect to earth?"

S1: "Drop a copper rod in the ground."

S5: "How do you earth a shack?"

Student 5 asked a very important question. This question reflects an important oversight in the curriculum as there is no content on earthing and lightning protection for informal dwellings. ${ }^{21}$ 
Textbooks rarely deal with challenges that people face in informal structures, yet these structures are commonplace throughout the developing world. In South Africa there are 2.6 million informal dwellings (excluding tribal dwellings) with an average household size of 3.3 representing about 15 percent of the population. ${ }^{22}$ This raises ethical questions regarding what should be included in the curriculum owing to a fair proportion of the students and/or their family who inhabit such dwellings.

People are at risk living in informal structures that have electricity supply but no earthing system. In November 2017, a young girl was electrocuted in her shack after her body touched the zinc sheet of the shack wall (Gontsana 2017) ${ }^{23}$. In this unfortunate case, the cause of the fault was the electrical supply cable which came into contact with the zinc. Many people use extension cords in a daisy-chain. These extension cords are connected directly to utility boxes which have insensitive earth fault protection (they are not designed to protect human life). When a live wire comes in contact with the zinc (possibly from a tear in the wire's insulation), the zinc becomes dangerous to touch. If the shack in question was earthed, the young girl's life would have most likely been saved.

The student who asked the question on how to earth a shack indicated to me that if there was no one else conversing in the classroom, he would not have asked the question owing to embarrassment. ${ }^{24}$ The conversational nature of the classroom creates a forum for open and candid learning whereby the teacher is also a learner. The teacher is attempting to converse and get to know the knowings of the students who sit in the class. In Figure 2, there is a steering icon which is meant to illustrate that both the students and the teacher steer the conversation which in turn informs the curriculum. Student 5 has now steered the conversation to an important topic of earthing informal dwellings.

S5: "How do you earth a shack? Continued ..."

T: "If the shack is made from zinc, we would need to bond all the zinc pieces together. We would then need to insert a copper rod into the ground at least one meter deep. This copper rod must be connected to the zinc in as many places as possible. This would mean that we could also have earth straps in the installation. Who knows what an earth strap is?"

No one knows.

T: "An earth strap is a flat copper band or strip that we can use to join two/more pieces of metal that are near each other but not close enough to be bonded together. You could think of it as a flylead. Why would we use this earth strap?"

S6: "If the current needs to flow to earth there must be a path. Since the shack wall (zinc) is not touching the copper rod, then we connect it using the earth strap."

S7: "This is silly, if someone installs a copper rod next to their shack, the next day it will be gone!"

Students chuckle. 
Student S7 has highlighted that theft is a problem and that copper, which has a higher value than zinc, will be stolen and sold for scrap. This student brings the challenge of crime into the curriculum which is a specific challenge to infrastructure design in South Africa and other countries that have a high crime rate. Textbooks dealing with earthing and lightning protection do not address this challenge of theft and thus this local experiential knowledge is of value to inform the course contents. Theft of infrastructure affects road signalling (traffic lights), power stability (electricity supply), radio networks and telecommunications. Drain covers, metal railings on sides of roads and so forth are often stolen for the value of the metal which is sold as scrap. While this is an annoyance to municipalities and the public, it also provides as an opportunity for innovative designers to create new methods for dealing with such challenges. ${ }^{25}$

T: “Am I correct in saying that shacks are often placed very close to each other?"

I (the teacher) do not have this knowledge and need to enquire from the students if anyone may have this knowledge about shack placements. A student provides me with an answer as follows:

S4: "In the rural areas they are spaced further away. Near towns they are cramped and spaced close to each other."

T: "I have seen some shacks have wood frames and some are mixed - wood and zinc. Can you tell me about the cladding?"

S10: "What is cladding?"

Students do not know the word cladding

T: "Cladding is like a layer that is put over the structural frame/walls. We talk of interior and exterior cladding. Examples include, tiling a wall, using glass as the exterior on a building. Think of it like the clothing you wear."

"When I asked about the cladding of a shack, I wanted to know more about the inside walls. I have seen hard board used on the inside of shacks. Can anyone tell me about this?"

S9: "Some shacks have boards on the inside and some don't. Some are mixed. People use lots of different things to cover the zinc walls."

T: "Am I correct in saying that many shacks have exposed zinc that people could touch by mistake? What do you think about this exposed zinc?"

Many students agree with this. Varying comments made.

S7: "Sir we know that if the zinc is hot (live) we can get a shock. People who don't understand electricity do not know that they must not touch live steel."

T: "Do you all understand what S7 said?" 
Not everyone understands how the zinc becomes live.

T: "S4, could you please explain the concept of a live chassis?"

S4: "If the shack has got electricity, then if the live wire touched the zinc it would be a danger to people who may also come into contact with the zinc."

S10: "It's because you are standing on the floor/ground which is at a zero voltage level. Then when you touch the live zinc, which is at $220 \mathrm{~V}$, you conduct the electricity through your body and gida (dance)!"

Students chuckle. Notice how this student (S10) provided an excellent explanation for electrocution.

T: "How can this be solved? Earlier we spoke of bonding the metal together. If all the zinc is joined together and we place an extra zinc on the roof that joins to another shack, then we have electrically connected two shacks together. This would be step one."

S3: "Why do we join the shacks together?"

T: "One of the principles of earthing is to join all metal above and below the ground so that there is no differential. This also allows for greater dissipation of fault current. Buildings/Houses are joined together by their steel water pipes, for example, which are buried under ground acting as part of the earthing system."

S2: "Shacks do not have gutters so how do we join the shacks together with an extra zinc. Where will the water go if it rains?"

This student has now introduced the topic of water drainage in earthing systems. This is an important topic as it also relates to how earthing systems are designed as well as the soil and resistivity aspects which affect earthing installations.

S5: "I don't think having extra zinc joining two shacks together is a good idea. It may get stolen if it's seen as extra. I would join them on the floor under the sand. Will that work?"

S1: "What if we puncture the zinc that is joining the shacks with holes so that the water can drain when it rains. The zinc won't be stolen as it's now useless with holes. It can still conduct fault current when it has holes, so it will still work. We can join the shacks with the zinc that is punctured."

From the two comments above it is clear that the students are trying to solve real life problems and in turn demonstrate an understanding of the principles of earthing while also accommodating local challenges that people face in communities.

T: "Do you know that many substations have something called an earth mat? This is a metal sheet or mesh of conductive material that is placed in the horizontal plane. For example, 
under a transformer in a substation. If the operator stands on the nearby ground, he/she is effectively at the same electrical potential as the machine and thereby minimises any differentials ...."

My role is to link the already present knowledge (or interests) to the other topics within the curriculum. If I started the class by just telling students how to earth a substation, there would have been minimal student participation and the knowledge would probably be compartmentalised. The conversations continue now with the addition of substation earthing.

The final solution: The outcome of the conversation was to use an underfloor zinc mat that would be bonded together between shacks under the sandy ground and if possible, on top with a punctured zinc sheet. The side walls of all the zinc pieces need to be joined together so that they are all electrically connected. The topics of how to bond the metal were covered. The students then may select their form of assessment for this topic. With my motivation, this section became a practical assessment that students can do as part of community involvement. This topic addresses a community related problem that a second or third year student could solve in their community within three hours.

\section{Summary of principles}

Figure 2 shows a representation of this process. The curriculum is floating and is not owned by any single entity but is influenced by and influences those who engage with it. The curriculum is a dynamic part of the education system perturbed by the teacher, students, and other interested parties who act as steering agents. Industrial partners have an important role as they represent the employers, the accreditation bodies, and other professional partners. The boundary around the industrial partners is closed which signifies the limited flow of information from this entity while the students and teacher have an informationally open boundary (dotted line), as they have access to each other and can openly engage in the classroom.

The use of circular shapes is meant to represent recursivity. There is no control, only mutual influence in the system - there is no hierarchy. If the reader imagines the outer loop as rotating, it is evident that there is no top or bottom. Each of the steering actors can influence the curriculum, which means that adaptation is prized in this approach. Without adaptation, the structure would not tolerate the eclectic approach to knowledge creation. This means that the educator's pedagogy must allow for adaptation. Cross pollination of ideas takes place in the shared context - the classroom spaces. Reflexion is achieved by the openness to review/comment/critique by any actor within the system. The actors are connected through their conversations which may at times be in other formats (written for example). As each semester 
has new students, and possibly a new lecturer, the curriculum too shifts as the curriculum is something that is experienced and not something that is objective. This whole process takes place in the context of society which also influences the ideas, thinking and beliefs that are on offer at that time.

\section{Moving from hierarchy to heterarchy (trust and care)}

Conversations occur when there are listeners who want to learn about the observing of another person. They are not simply spaces for people to hear their own voices. Socratic questioning has minimal value in this approach although is useful as a conversation starter (exemplified in the first part of the dialogue). The goal is not to see if the students know the right answer. The goal is to understand how the students understand the topics. This entails what Anderson and Goolishian (1992) have termed a not knowing stance. In this approach, even though I am the specialist in the field of study that the students wish to master, I simply do not know the knowings of the students. If I am attempting to engage the students in a conversational manner whereby they co-author the curriculum, I must be willing and tolerant (which can be challenging) while also being generous and trusting, aligning to Ubuntuism. ${ }^{26}$ Glanville (2001) highlights that for conversations to support variety, there needs to be an interest in learning and enjoyment of difference, which relies on trust and care. Without a personal interest in the conversation and the views of the other, no new creative understandings can emerge.

\section{IMPLICATIONS OF CONVERSATIONAL TEACHING AND LEARNING}

\section{Increased student involvement}

One of the questions people have regarding this approach, is whether students participate or want to participate (c). Abstract engineering topics that rely on imagination are challenging to get students to pay attention to as they have no personal linkage to the topic. However, when the course content is relevant to the people who use it, it becomes alluring. When the content becomes personal, it becomes interesting. The increased involvement in my classes was measured by participation in the class and the increased attendance. There has also been an increase in students' eagerness in completing work packages.

\section{Increased understanding as opposed to rote learning}

In terms of the shack earthing example provided, the principles that were discussed are equally valid in substation earthing, for example. The students are then able to adapt to the different contexts, now being able to link their knowledge from the already present topics in their 
knowledge store. The conversational approach allows people to clarify their thinking, put their thinking in their own words, and compare it with other actors within the classroom. This ongoing reflexive process is a form of deep learning. The conversations are spontaneous, unpredictable, and live which all assists in the content being memorable.

\section{Increased responsibility}

When students are provided the option to steer and co-create the curriculum, they in turn take responsibility for this. For example, when a student offers a topic for enquiry, this student is activated to follow through and listen to other students who converse on this topic. The topic is in some way linked to the proposer and often he/she wants to nurture or develop it. Care is an interesting outcome. Students demonstrate care in their comments/work. The feedback is that since the content is something that students can use immediately in their own life and is relevant to their own knowledge, they care about this content.

\section{Early warning for challenging topics}

Pass rates are a contentious issue and lecturers are often requested to improve their throughput rates with some departments even putting this requirement in their key performance indicators. A continuous stream of poor student marks are a reflection on the educator. However, if the educator takes a vocation of teaching and learning, it goes without saying that the educator would like the students to do well, irrespective of the university's pass rate requirements. Some educators provide additional assessments in the hope that failing students will improve their marks. However, why let the tests and exams alone be the measure of student progress? Through conversational teaching and learning, the educator can quickly get a snapshot of the weak spots in the syllabus. When conversing with students, simply asking questions and hearing answers or hearing students' interpretations on the topics, allows the teacher to ascertain if he/she has been an effective teacher or not. ${ }^{27}$ This early warning allows the teacher to address the problems prior to the assessments.

\section{Improvements in students' assessment marks}

When the students get a chance to converse about their understanding in community with others, it's a form of studying. The students, through their listening and speaking, provide a continuous revision exercise as they comment and reflect on each other's comments. When the content is personally reinterpreted and understood by the students, the assessment marks are higher. This has been empirically tested by the author (Baron and Baron 2015). 


\section{Interdisciplinary holistic learning}

The earlier example of the mechanical friction being used as a basis for explaining electrical friction, highlights the holistic view of knowledge creation in this approach. It is problematic for educators when then they think the students compartmentalise their knowledge, not linking the knowledge across disciplines or subjects. The university and its very clear boundaries separating faculties underscores this point, which I argue, is old fashioned and colonial. Interdisciplinary thinking is a viable option for the complex world with social injustices and its wicked problems. In conversational teaching, there is openness to bring in any information that the actors may think is relevant.

\section{An unexpected finding}

Not every student is interested in participating in curriculum design. A few students over the years have indicated that they are content to just be told what to study. These students do engage in the class but feel that the teacher can just direct all the learning. This small group of students show high motivation in their learning and generally are top achievers. This would mean that conversational teaching and learning is specifically relevant for students who need the extra support or students who do not have high motivation for their studies. Informally testing this hypothesis has shown that most students do not have high motivation for their studies for various reasons (preferred degree full, parents' choice of study field, studying to get a job and so forth).

\section{CHALLENGES}

\section{Uncommon approach: Paradigm shift}

Within most mainstream universities, conversational teaching and learning is uncommon for both the students and the lecturers. The curricula, assessment methods, and pedagogies on offer do not cater for this paradigm shift (Baron 2014; Scott 2011). Many educators who are interested in an eclectic constructivist approach have not been exposed to a cybernetic epistemology, even with the abundance of literature on communication systems. This acts as a boundary when trying the approach as it may be seen as too radical.

Some educators are worried that allowing increased student involvement in the curriculum would end up with a chaotic outcome. My findings are that this does not happen (Baron 2016a). Students want the teacher to act as leader but enjoy the idea of personalising and adapting a curriculum making it in service of the community. 


\section{Large classes}

Conversational teaching and learning works well in classes with less than 60 students. However, in larger classes, sampling is an option whereby the educator could sample from the most common student inputs. However, Herr $(2013$, 2014) has shown that constructivist conversational formats are possible with larger groups.

\section{Outcomes and accreditation bodies}

There is a fear that if the curriculum is opened to the students, there will be loss of accreditation owing to the uncontrolled ad hoc changes being made. There is also a perception that the syllabus is a locked part of the curriculum and that if the content is changed, the outcomes of the module will be affected. These two concerns speak to question (d) in the aforementioned list.

In the public schooling context the syllabus is set centrally and thus changing the syllabus is more challenging, although not impossible. However, in the university context, the lecturers are the ones who mostly populate the content from their specialisation in the field they teach. The outcomes of a certain qualification may be set by accreditation bodies and/or industry partners ${ }^{28}$ however, the content and application of the content does have a considerable range within which the lecturers may act. In the earlier example of the networks systems module, the students opted for Bluetooth encryption for wearable devices. This topic falls under the subject area of network protocols. Since this still falls under the umbrella of computer networking and is not covered in any other module in the computer engineering course, it is a favourable improvement to the course content. One cannot keep adding content and thus there is a requirement to review what could be omitted from the module. The topic of frame relay was omitted which was an older method of telecommunications. It is a challenging process to decide what to remove. I have answered this question by critically evaluating which topics the students would more likely need. In the said case, the Bluetooth encryption is a viable option over the dated frame relay.

\section{DISCUSSION: KNOWLEDGE CREATION AND SOCIAL JUSTICE}

The outcomes that learners in the South African education system should achieve include creativity, problem solving, higher-order thinking skills, reasoning, improved effective communication, interpersonal skills, public speaking, teamwork and collaboration (DoE 2004, 16). ${ }^{29}$ However, the idea that students must move through the education system like cattle does not seem congruent with the outcomes that the graduate should have acquired. Designing the 
course content without the inputs of those who are the co-authors of the content seems illogical and unethical when the teacher learner system is relational. Imagine having a conversation with someone who has already prepared all their answers. I have in turn changed my approach to teaching and learning whereby curricula should be designed for openness with a pedagogy that is dynamically adaptable.

The purpose of teachers is that they differ from a search engine (pointing the student to information), they differ from a study guide (providing the rules for the student), and they differ from the textbooks (providing the topics to study). The role of the teacher is no longer just a person with the information - and those educators who think this is their primary task may soon be out of work. I argue that the role of the teacher is the human who is in the "here and now" adapting according to the other actors in the class, often allowing for excitement, spontaneity, and fun. This is based on a feature in counselling psychology called immediacy (Rogers 1980). Immediacy challenges a person to attempt to know what it is like to be in the shoes of another. I have realised that every person has their own epistemology. Griffith, Griffith and Slovik (1992) challenged practitioners to take responsibility and own their own epistemology in conversations. Hearing the understandings of other people may challenge one's own understandings. The classroom too can be a challenging arena. After years of teaching, I want to be challenged so I may sustain this vocation, as it makes the class more interesting and fun, and simultaneously contributing to my own wellbeing.

In this approach, a paradigm shift may be required for some educators in which there is a move from transmitting information and correcting students, to one of meaning creation in community with one another. This social learning creates the space for the individual experiences of the curriculum to be explored, embracing the worldviews of the actors within the classroom, and in so doing, aiming to address social justice.

Attempting a humanising pedagogy assumes the lecturer has an interest and care for the students. There is an underlying critical awareness of the social and political aspects that may be hindering certain groups of people, while also acknowledging the connectedness in the human family. Since a family cannot thrive when some members are suffering (Baron 2017), there is thus a goal to reimagine the world for the upliftment of all. This is enacted by the authentic lecturer who focusses on the students' educational goals (Pask 1976a), even if these goals may initially seem off the topic (earthing a shack). A humanising approach provides students with an opportunity to ask questions that reflect their own challenges and have these questions addressed on an equal footing to others in the shared classroom space.

One of the requirements for accreditation bodies is that there must be proof of learning. In the conversational teaching approach, the learning is taking place right in front of the teacher. 
There is a sense of wellbeing as it is enjoyable to be part of mutual learning and upliftment. The students have their teacher and their peers at their disposal while learning. The learning is memorable as it is inclusive of the personal understandings of the learners. The teacher can use tests and exams as additional proof of learning, but verbal presentations are worthwhile. In most job applications, it is the interview where employers "see for themselves" if they are convinced that the applicant is as good as their CV claims.

\section{NOTES}

1. Teaching portfolios have become a requirement for promotion applications in many universities.

2. In October 2015, the protest action at South African public universities raised the point of decolonisation of knowledge. This and earlier protest movements highlighted the inherited and unresolved legacies from the apartheid regime.

3. In 1951, the government set up the Eiselen Commission to review native education which was the precursor to the Bantu Education Act No.47 of 1953 (Potgieter 1976). The recommendation from the commission was that there should be a carefully planned policy of segregated socio-economic development for black people (Christie and Collins 1982). The outcomes of the resultant Act No.47 continued the racial segregation. There was a view that black children (non-Europeans) should not be given an academic education as these children would grow up to perform low skilled manual labour; hence, the academic education should be for the Europeans (Eiselen 1951).

4. International students are excluded from this statistic. University of Johannesburg ANNUAL REPORT 2016, (2016, 126) https://www.uj.ac.za/about/Documents/Annual\%20 reports/ UJ AnnualReport2016_DHET_Digital\%20(final\%2027\%20June\%202017).pdf

5. There has been an increase in African academic staff in South African public universities; however, the progression from lecturer to professor does take considerable time. For example, the faculty of engineering at the University of Johannesburg has 25 associate professors of which eight are black and nine are white.

6. Being both a participant and speaker at many workshops on decolonisation of knowledge, I observed that many academics assumed that simply amending their courses to include some local content was an answer to the Africanisation of the curriculum.

7. The author has used this approach in classes at the University of Johannesburg in the department of Electrical and Electronic Engineering from 2012 onwards. The class sizes ranged from 12 to 80 students. The following research articles are available for the interested reader (Baron and Baron 2015; Baron 2016a; 2016b; Baron 2017; Baron and Herr 2019). The author was awarded UJ's Vice Chancellor's award for teaching excellence in 2015 as well as the CHE award for teaching excellence in 2016.

8. Teaching in foreign countries highlights the differences that exist across cultures. For example, Western educated academics who teach in a Muslim Arab nation in a university or college that comprises of only female students, poses several cultural adaptations for the educators and students (Sonleitner and Khelifa 2005). Another example includes Western educated teachers who teach in China. The cultural norms and values of the society are relevant to the educator's pedagogy (Degen, Absalom and Australia 1998; Baron and Herr 2019).

9. This term is meant to describe the influence the researcher's own bias or presence adds to the outcomes of the research. Anthologist and cyberneticist Margaret Mead (1943) realised that her mere presence in the cultures and groups she was studying impacted their behaviours; her presence within the system (group) impacted these very systems.

10. This departs from the tabular rasa view or what Freire (1996) termed the "banking model of education", i.e. treating students as empty vessels that can be filled like a piggy bank. 
11. The open invitation for students to contribute remains part of the approach from the first lecture of the semester.

12. Wearable computers or wearables are small scale electronic devices that are worn under or on top of clothing. Smart watches, fitness trackers, and heart rate monitors are some examples.

13. The outcomes of the module are unaffected as the outcomes reflect the student's ability to demonstrate a skill that is not necessarily tied to the content (explained further in the section dealing with challenges).

14. This method also shows students that knowledge should not be compartmentalised but intermingled as there is considerable overlap in principles across many disciplines.

15. Unpublished manuscript "Metadesign" http: //www.inteco.cl/articulos/metadesign.htm

16. From a biological perspective, it may be argued that our thoughts and experiences are mapped in our neurology (Maturana and Varela 1987). This would mean that epistemology is biological adaptation.

17. Albert Bandura $(1973,1977)$ and his work on Social Learning Theory (SLT), including vicarious learning, has found that peers are an important aspect in the learning system. When students are given the opportunity to teach their peers, the other students tend to pay attention owing to the strong identification they have with one another.

18. A pilot study on Teachback in a pre-school showed that the teacher who used Teachback had her learners score higher on memory retention tasks when compared to a traditional teaching style (Baron and A. Baron 2015a).

19. The earthing standards are set out by various local and international bodies. These include the Institute of Electrical and Electronics Engineers (IEEE 1982), such as standard 142-2007; and the International Electrotechnical Commission (IEC) - standard 60364-1 (IEC 2005). An example of a local standard includes the South African National Standard (SANS) 10142-1:2009 (SANS 2009. There are many earthing standards owing to the numerous applications and localities.

20. The new content is not fixed in the curriculum as the next group of students may provide new topics.

21. The SANS 10142-1:2009 (SANS 2009) standard does have a short section that relates to surge protection devices installed in various dwelling types. This is only relevant when there is an earthing system installed.

22. "South Africa: Informal settlements status." The Housing Development Agency, Johannesburg SA. http://www.thehda.co.za/uploads/files/HDA_Informal_settlements_status_South_Africa.pdf (Accessed 1 December 2017).

23. See "Woman electrocuted by her shack in Marikana" by Mary-Anne Gontsana in GroundUp . https://www.groundup.org.za/article/woman-electrocuted-her-shack-marikana/ (Accessed 5 December 2017).

24. All students, irrespective of their socioeconomic status, should feel equally important in the classroom. A humanising pedagogy entails a commitment to social justice with an ethical attitude toward equality. Embracing a critical consciousness (see Freire 1996) which entails analysing, questioning, and challenging oppressive conditions that people live under (Bell 2016).

25. South African alarm systems and gate automation, for example, are sold in many countries competing with the best in the world.

26. Ubuntuism is used in the context of mutual respect.

27. I have argued that students sitting in the teacher's class are the people who can provide the label of "good teacher". The attribute is not owned by the teacher but something the teacher may be given by those who experience the teacher as a good teacher. Thus, this same teacher may be labelled an ineffective teacher by another group of students (Baron 2016a). This has implications for teaching awards that do not include the views of the student groups.

28. There are certain outcomes that the graduating student needs to meet to achieve professional registration. This also entails certain requirements that the respective faculty within the university 
need to adhere to. Interestingly, the accreditation bodies do not necessarily declare the teaching approach, nor the assessment method, nor the exact content. In the case of electrical engineering, the accreditation body (Engineering Council of South Africa) specifies the outcomes that the graduate should achieve after completing their study

[Forms for use in accreditation visit documentation. Engineering council of South Africa. Revision 2 (31 July 2014). https://www.ecsa.co.za/education/EducationDocs/E-13-P.pdf (Accessed August 2015)].

29. These goals are not specific to the South African context, as it is obvious that these skills are favourable to any graduate.

\section{REFERENCES}

Anderson, Harlene and Harold Goolishian. 1992. The client is the expert: A not-knowing approach to therapy. Therapy as Social Construction (1992): 25-39.

Austin, John Langshaw. 1962. How to do things with words. Oxford university press.

Bandura, Albert. 1973. Aggression: A social learning analysis. Prentice-Hall.

Bandura, Albert and Richard H. Walters. 1977. Social learning theory. Vol. 1. Englewood Cliffs, NJ: Prentice-hall.

Baron, Philip. 2014. Overcoming obstacles in learning cybernetic psychology. Kybernetes 43(9/10): 1301-1309.

Baron, Philip. 2016a. A Cybernetic Approach to Contextual Teaching and Learning. Constructivist Foundations 12(1).

Baron, Philip. 2016b. The role of context in decolonising engineering curriculums in proudly South African universities: a cybernetic perspective. In Proceedings from the 6th African Engineering Education Association conference (AEEA 2016), ed. A. J. Swart, 167-173. Central University of Technology, Bloemfontein SA. http://www.cut.ac.za/wp-content/uploads/2015/11/2016-AEEAConference-Proceedings-Final1.pdf

Baron, Philip. 2017. Changing perspectives in the face of the decolonisation of knowledge at South African public universities: A case for family therapy. Kybernetes 46(9): 1564-1577.

Baron, Philip and Anne Catherine Baron. 2015. A quantitative examination of two different teaching paradigms in a Germiston based pre-school: A pilot study. Kybernetes 44(8/9): 1207-1218.

Baron, Philip and Anne Catherine Baron. 2019. Ethically resilient educators: What might that be?: A comparison across two educational levels: Pre-school and university in South Africa. Kybernetes. https://doi.org/10.1108/K-01-2018-0033

Baron Philip and Christiane Herr. 2019. Cybernetically informed pedagogy in two tertiary educational contexts: China and South Africa. Kybernetes 48(2): In press.

Bell, Lee Anne and Maurianne Adams. 2016. Theoretical foundations for social justice education. In Teaching for diversity and social justice, 21-44. Routledge.

Bartolome, Lilia. 1994. Beyond the methods fetish: Toward a humanizing pedagogy. Harvard Educational Review 64(2): 173-195.

Bateson, Gregory. 1972. Steps to an ecology of mind: Collected essays in anthropology, psychiatry, evolution, and epistemology. University of Chicago Press.

Broadbent, Donald Eric. 1971. Decision and stress. London: Academic Press.

Christie, Pam and Colin Collins. 1982. Bantu Education: Apartheid ideology or labour reproduction? Comparative Education 18(1): 59-75.

Daniel, J. 1998. VC's View. Sesame, The Open University's Newsletter, April/May: 12.

del Carmen Salazar, María. 2013. A humanizing pedagogy: Reinventing the principles and practice of education as a journey toward liberation. Review of Research in Education 37(1): 121-148. 
Degen, Tang, Doug Absalom and C. Australia. 1998. Teaching across cultures: Considerations for Western EFL teachers in China. Hong Kong Journal of Applied Linguistics 3: 117-132.

Department of Education. 2004. White paper on e-education transforming learning and teaching through information and communication technologies (ICTs). Government Gazette No. 26734. South Africa.

Department of Higher Education and Training. 2017. Statistics on post-school education and training in South Africa: 2015.

DoE see Department of Education.

DoHET see Department of Higher Education and Training.

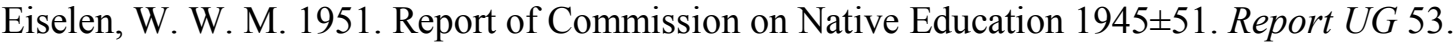

Freire, Paolo. 1996. Pedagogy of the oppressed (revised). New York: Continuum.

Foerster, H. von. 1991. Through the eyes of the other. In Research and reflexivity, 63-75.

Glanville, Ranulph. 2008. A cybernetic musing: Five friends. Cybernetics and Human Knowing 15(34): $163-172$.

Glanville, Ranulph. 2001. An observing science. Foundations of Science 6(1-3): 45-75.

Glanville, Ranulph. 2013. Cybernetics: Thinking through the technology. In Traditions of systems theory: Major figures and contemporary developments, ed. D. Arnold, 45-77. Routledge, New York.

Griffith, James, Melissa Griffith and I. S. Slovik. 1992. Owning one's epistemological stance in therapy. Dulwich Centre Newsletter 1: 5-11.

Glasersfeld, Ernst V. 1992. Guest editorial. Educational Studies in Mathematics 23(3): 443-444.

Glasersfeld, Ernst V. 2007. The constructivist view of communication. In An unfinished revolution? ed. A. Müller and K. H. Müller, 351-360. Vienna: Echoraum.

Herr, Christiane M. 2013. Qualitative structural design education in large cohorts of undergraduate architecture students. Global Journal of Engineering Education 15(2): 96-102.

Herr, Christiane M. 2014. Radical constructivist structural design education for large cohorts of Chinese learners." Constructivist Foundations 9(3).

IEC 60364-1. 2005. Installations - Part, L. V. E. 1: Fundamental principles, assessment of general characteristics, definitions.

IEEE. 1982. Industry Applications Society. Power System Technologies Committee. IEEE recommended practice for grounding of industrial and commercial power systems Vol. 142. IEEE.

Kelly, G. 1955. The nature of personal constructs. The Psychology of Personal Constructs 1: 105-183.

Landa, L. V. 1971. The Algorithmicization of Instruction, ed. F. Kopstein. Translated by V. Bennet. Manuscript copyright. Educational Technology Publishers. Englewood Cliffs, N.J.:

Laurillard, Diana. 2013. Rethinking university teaching: A conversational framework for the effective use of learning technologies. Routledge.

Luria, Alexander. R. 1961. The role of speech in the regulation of normal and abnormal behaviour. London: Pergamon Press.

MacIntyre, Alasdair. 1987. Relativism, power, and philosophy. In After philosophy: End or transformation, ed. K. Baynes, 385-409. MIT Press. Cambridge, MA.

Maturana, Humberto R. and Francisco J. Varela. 1987. The tree of knowledge: The biological roots of human understanding. New Science Library/Shambhala Publications.

Mead, Margaret. 1943. "Our educational emphases in primitive perspective." American Journal of Sociology 48(6): 633-639.

McCulloch, Warren. S. 1965. Embodiments of mind. MIT Press. Cambridge, Mass.

Miller, George A., Eugene Galanter, and Karl H. Pribram. 1960. Plans and the structure of behavior. 
Holt. New York.

Pangaro, Paul. 2001. THOUGHTSTICKER 1986: A personal history of conversation theory in software, and its progenitor, Gordon Pask. Kybernetes 30(5/6): 790-807.

Pask, Gordon. 1975a. The cybernetics of human learning and performance: A guide to theory and research. Hutchinson Educational, London.

Pask, Gordon. 1975b. Conversation, cognition and learning: A cybernetic theory and methodology. Elsevier, Amsterdam.

Pask, Gordon. 1976a. Styles and strategies of learning. British Journal of Educational Psychology 46(2): 122-148. http://cepa.info/3941

Pask, Gordon. 1976b. Conversational techniques in the study and practice of education. British Journal of Educational Psychology 46(1): 12-25.

Piaget, Jean. 1959. The language and thought of the child (Vol. 5). Psychology Press.

Potgieter, Dirk Jacobus and P. C. du Plessis. 1976. Standard Encyclopaedia of Southern Africa. Nasou.

Richards, Larry. 2014. Education as a subversive activity: A proposal. Kybernetes 43(9/10): 1392-1398.

Rogers, Carl. 1980. A way of being. Houghton Mifflin Company, New York, NY.

SANS 2009. 10142-1:2009. The wiring of premises. SABS Standards Division. Groenkloof. Pretoria.

Schön, Donald A. 1983. The reflective practicioner: How professionals think in action. Vol. 1. New York: Basic books.

Scott, Bernard. 2000. CASTE revisited: Principles of course design in a hypertext environment. Information Services \& Use 20(2-3): 117-124.

Scott, Bernard. 2011. Explorations in second order cybernetics. Edition Echoraum, Vienna.

Sonleitner, Nancy and Maher Khelifa. 2005. Western-educated faculty challenges in a Gulf classroom. Learning and Teaching in Higher Education: Gulf Perspectives 2(1): 1-21.

Thomas, Laurie and Sheila Harri-Augstein. 2001. Conversational science and advanced learning technologies (ALT) Tools for conversational pedagogy. Kybernetes 30(7/8): 921-954.

Thoreau Henry. D. 2006. Walden. Yale University Press, New Haven CT.

Welford, Alan Traviss. 1968. Fundamentals of skill. Methuen. London. 